\title{
As Faces de Hécate: formas narrativas na produção do acontecimento
}

Sônia Maria de Meneses Silva

\section{Resumo}

Este artigo analisa a produção do acontecimento contemporâneo colocando em relevo a sua formulação a partir de três perspectivas: a Literatura, a Mídia e a História. Tendo como base as proposições de Paul Ricoeur, investigamos como a ação narrativa efetiva espaços de construção de sentido tanto no texto como fora dele. Debruçamos-nos sobre a tripla narrativa da obra A Guerra dos Mundos: texto literário de H. G. Wells, texto midiático de Orson Welles e discussão histórica sobre os efeitos desencadeados pelo programa de rádio veiculado em 1938.

Palauras-chave:

Acontecimento, Narrativa, Literatura, Mídia e História

\section{The faces of Hecate: narrative forms in the production of events}

\section{Abstract}

This article analyzes the production of the event contemporary placing in relief its construction in three approaches: Literature, the Media and History. Having as base the proposals of Paul Ricoeur, we investigate as the action narrative constructs ways as much in the text as is of it. In them we lean over on the triple narrative of The War of the Worlds: literary text of H. G. Wells, media text of Orson Welles and the historical reflection on the effect unchained for the program

\section{Sobre a autora}

Doutoranda em História na Universidade Federal Fluminense-UFF; Docente do departamento de História da Universidade Regional do

Cariri-URCA. sonia.meneses@gmail.com of radio propagated in 1938.

Key words:

Event, Narrative, Literature, Media end History 
Das divindades gregas, Hécate é talvez uma das menos conhecidas. Deusa estranha, cujo nome significava "a distante", era representada por três corpos e três cabeças que a ligavam a três mundos: o céu, a terra e o submundo. Porém, uma propriedade é ainda mais peculiar: Hécate tinha o poder de olhar para três direções ao mesmo tempo. Era a deusa feiticeira que ajudava aos homens compreenderem seus caminhos. Embora não estando entre os deuses mais populares da mitologia grega, a divindade carrega o dilema que parece realçar algumas das angústias mais antigas do homem: a busca de compreensão sobre os acontecimentos a sua volta e sobre o tempo; sobre nosso olhar sempre (tri) partido entre passado, presente e futuro.

Nesse texto, refletiremos como uma narrativa enseja estratégias da ação humana e constrói fatos marcantes a partir disso, buscaremos compreender como se relacionam formas diferentes de narrar uma mesma história. Tal elemento hoje é fundamental para pensarmos como ocorre a formulação de sentidos entre a Literatura, a Mídia e a História.

Tentaremos experimentar o alcance das proposições de Paul Ricoeur em uma obra que, curiosamente, tornou-se um dos textos de apropriações mais complexas da contemporaneidade: A Guerra dos Mundos. Obra literária de H. G. Wells e texto midiático de Orson Welles. Nestas, as tênues fronteiras entre realidade e ficção se embaralharam, desconcertantemente, desafiando nossas fixas noções de real e imaginário, passado, presente e futuro. Ao primeiro olhar, um perfeito exemplo para vislumbrarmos a tríplice mimese da qual fala Paul Ricoeur. Por último, interessar-nos-á a elaboração do acontecimento histórico na dialética entre verdade e ficção. Portanto, ousaremos estabelecer um diálogo com estes três campos, buscando identificar seus elos e conexões.

\section{A construção do acontecimento midiático na tessitura literária}

Talvez eles também rezassem confiantemente a Deus. Se aprendemos alguma coisa com essa guerra, seguramente foi a piedade - piedade pelas almas ingênuas que sofrem nosso domínio. (WELLS, 2007:. 201)

A descoberta do outro talvez tenha sido o verdadeiro achado do europeu em suas expedições de invasão pela África, Ásia e América. Entretanto, ao contrário da compreensão sobre a diferença, o mundo moderno viu nascer, de forma pungente, os argumentos da superioridade racial e cultural como justificativas para a dominação, intolerância e a indiferença. Em fins do século XIX, vivia-se o último grande movimento das invasões modernas desencadeado pelas potências européias. O retorno aos continentes, anteriormente conquistados, explicava-se principalmente pelas novas necessidades da economia capitalista em plena expansão.
Ao contrário da compreensão sobre a diferença, o mundo moderno viu nascer, de forma pungente, os argumentos da superioridade racial e cultural como justificativas para a dominação, intolerância e $a$ indiferença 
O final do século XIX era também a ocasião na qual concorriam várias temporalidades: o tempo rápido da racionalidade científica; a busca incessante pelas novidades na consolidação dos grandes espaços urbanos. A corrida por novas tecnologias de comunicação com a modernização dos sistemas postais e ferrovias ligando vários continentes; tempo do capital, do relógio e do apito da fábrica. Uma temporalidade frenética segunda a qual o futuro era o lugar do progresso, da civilização e da superação das limitações humanas frente à natureza.

Mas o século XIX era também um tempo de incertezas para outros povos marcados pela violência das invasões e pelos processos de re-colonização. Tempo imperialista de angústias, destruições; tempo lento da intolerância. Para a própria Europa era também um tempo de tensão entre vários países, disputas de territórios e eminência de guerras.

É neste mundo atormentado e inquieto que Herbert George Wells lança, em 1898, A Guerra dos Mundos romance de ficção científica que se tornou um marco nesse gênero narrativo para as gerações posteriores. Nele o autor narra a fantástica história de uma invasão de marcianos sobre a terra, mais precisamente na Inglaterra. O mundo configurado na obra de Wells é a Europa, que, partindo de uma visão eurocêntrica, podia representar a humanidade e sua civilização.

Contudo, A Guerra dos Mundos questiona a própria condição humana e a fragilidade dessa civilização em plena época moderna, uma vez que leva os homens de sua obra a um retorno primitivo, em busca de sobrevivência e liberdade. O que, para aquela sociedade, eram condições, inquestionavelmente, adquiridas no curso do processo civilizador (Elias, 1997). Chega a ser desconcertante forma rápida como Londres é sobrepujada:

Era como um estouro de boiada, gigantesco e terrível, sem ordem nem direção; seis milhões de pessoas, desarmadas e desprovidas, avançando cegamente. Era o começo do fim da civilização, do massacre da espécie humana. (Wells, 2007:148.)

Wells finaliza sua obra com uma solução simples, porém embaraçosa. Nenhuma moderna arma, tão pouco os avanços tecnológicos, conseguiram representar qualquer empecilho à caminhada dos invasores; os marcianos são derrotados por bactérias.

Antes de mergulhamos no mundo do texto construído por Wells, é preciso que percebamos que o mundo do próprio autor é o espaço de pré-compreensão de sua obra, impregnado-a de códigos e significados. Como nos lembra Ricoeur, é o mundo das experiências temporais no qual concorrem vários signos e símbolos e é, partindo dessa compressão, que a intriga ampara sua contextu-
O mundo configurado na obra de Wells é a Europa, que, partindo de uma visão eurocêntrica, podia representar a humanidade e sua civilização 
ra; na ação, na densidade complexa da vivência humana em seus aspectos e riqueza. É o mundo no qual o autor busca referências para sua obra; sem ele, a tessitura de sua intriga dificilmente poderia se tornar um todo coeso e inteligível.

O mundo tecido por Wells, aquele que Ricoeur denomina como o espaço da Mimese II, por mais fantástico que possa nos parecer, busca seus fundadores de sentido em uma gramática da ação viva cheia de significados. Antes chegarem ao mundo configurado da obra, os marcianos de Wells estavam, enquanto possibilidade, em seu próprio mundo. A especulação sobre outros planetas e outras civilizações já era uma recorrência no imaginário, não somente do Europeu, mas de vários outros povos. Embora ficcional, estruturas mentais faziam de sua história um evento possível, verossímil, para Ricoeur (1997:88) graças “às mediações simbólicas da ação" presente naquele contexto.

$\mathrm{Na}$ primeira mimese da trama, o mundo do autor se manifesta em de três traços fundamentais: estruturais, simbólicos e temporais. Isso faz com que cada obra esteja inserida em um dado contexto cultural e simbólico de mediações. O mundo que antecede a intriga é parte fundamental de sua própria tessitura, por sua vez é rico também em narrativas e ações, fazendo com que autor e seus futuros leitores estejam imersos em um conjunto de relações e intersignificações que permitem a cada membro envolvido nessa rede ter uma competência prática para compreender a intriga.

Como escritor Wells partilhava com seus contemporâneos os efeitos de um mundo em guerras e em conquistas incessantes, como mencionamos anteriormente, para muitos críticos, a própria Guerra dos Mundos é uma metáfora mordaz contra os processos de recolonização afro-asiático. Com seus invasores, vindos de outro mundo, Wells lança um olhar crítico para a própria humanidade, vista como irascível e incompreensível em muitos de seus aspectos como podemos observar nessa passagem de sua obra:

\footnotetext{
Mas antes de julgarmos com muita severidade, lembremos a destruição cruel e completa que nossa própria espécie impôs não só a animais, como os extintos bisões e dodôs mas a suas próprias raças menores. Os tasmanianos, apesar da aparência humana, foram inteiramente dizimados numa guerra de extermínio promovida por imigrantes europeus no espaço de cinqüenta anos. Será que somos realmente apóstolos da tolerância, para nos queixarmos agora que os marcianos nos combatam com a mesma mentalidade.? (Wells,2007:31)
}

A citação destaca dois pontos fundamentais efetivados na tessitura da intriga: no primeiro nos apresenta uma compreensão prática do próprio mundo do autor - a reflexão sobre os movimentos de conquista em seu tempo é um exemplo disso -, o que 
podemos definir como uma ordem paradigmática, que estabelece uma interconexão horizontal de significados. Ou seja, não há a necessidade de uma ordem clara para que os signos se expliquem, uma vez que "todos os termos relativos à ação são sincrônicos no sentido de que as relações de intersignificações que existem entre fins, meios, agentes, circunstância são perfeitamente reversíveis" (Ricoeur, 1997:90).

Percebemos como o próprio Wells, crítico às invasões, não consegue se desvencilhar das estruturas de pensamento de seu tempo, sobretudo quando apresenta os outros homens como "raças menores", reafirmando o discurso da superioridade racial européia, tão marcante no seu tempo.

$\mathrm{O}$ segundo elemento do extrato efetiva traços discursivos que fazem do texto mais do que o mundo que ele pré-figura - podemos perceber a obra como sendo uma crítica à própria humanidade; uma narrativa que enseja também questões existenciais e subjetivas acerca da própria condição humana frente ao seu futuro. Sendo assim, manifesta-se o espaço de uma ordem sintagmática numa elaboração discursiva que tenta construir um sentido geral para a trama composta.

Há, portanto, uma formulação de sentido que é vertical, pois exige uma ligação clara entre os signos que implica um caráter diacrônico, ou seja, histórico, dessa forma, "passando da ordem paradigmática da ação à ordem sintagmática da narrativa, os termos da semântica da ação adquirem integração e atualidade" (Ricoeur, 1997:91). Ambas ajudam a compor uma história possível de ser acompanhada tanto em termos pragmáticos como conceituais.

Várias ordens e temporalidade podem engendrar uma mesma trama, competindo em jogos narrativos que tornam a intriga o espaço de uma liberdade elástica, porém, presa em uma relação dialética entre uma imaginação regrada e outra criadora. Ricoeur faz uma clara referência à Clifford Geertz (1978), demonstrando que, compreender o mundo de Mimeses I é, sobretudo, realizar um mergulho na densidade dos sistemas de significações simbólicas. Somente assim, será possível se reconstruir a teia de significados que dão inteligibilidade a um determinado ato.

Do mundo do autor passamos ao mundo do texto. A configuração da obra, ou o reino do "como-se", "sua função de mediação entre o montante e a jusante da configuração. Mimese II só tem uma posição de mediação porque tem uma função de mediação" (Ricoeur, 1997:102).

O caráter de mediação da narrativa não se manifesta somente na organização de um mundo próprio da obra, ela efetiva também uma, ou várias temporalidades. Torna o tempo mais do que um conceito e o faz existir como categoria compreensível a partir do ato narrativo.
Há, portanto, uma formulação de sentido que é vertical, pois exige uma ligação clara entre os signos que implica um caráter diacrônico, ou seja, histórico 
Mesmo que o autor não especifique precisamente o recorte temporal no qual se passa sua obra, há inúmeras referências dando possibilidade para que o leitor, a partir de suas próprias categorias de reflexão, consiga se situar em termos de uma temporalidade coerente:

Ninguém, teria acreditado, nos últimos anos do século XIX, que este mundo era atenta e minuciosamente observado (...) E, no início do século XX, veio a grande desilusão" (31) Ou ainda: "O problema toma forma nas primeiras décadas do século XIX...(Wells, 2007:33)

Nestes breves trechos percebemos que ele joga com a ordem temporal fora do texto. O evento todo se passa no espaço de quinze dias, mas as categorias de passado e futuro são pilares fortes de expectativa e referências, estabelecendo assim, marcos entre uma temporalidade fora do texto e o tempo configurado da obra. Tal formulação permite ao leitor compreender que a história se passa em um tempo diferente do seu, mas próximo a ele. Guerra dos Mundos efetiva também o tempo do padecer a da espera ansiosa ao criar uma sensação temporal que é concomitantemente tensa e angustiante e que oscila entre pessimismo e esperança.

\begin{abstract}
Nossa visão do futuro humano deverá ser radicalmente modificada por esses eventos (...) Essa invasão (...) livrou-nos da serena confiança no futuro que é a mais pródiga crença de decadência. Antes da queda do cilindro, a crença geral era de que em toda a amplidão do espaço não existia vida além da superfície de nossa esfera (...) Se os marcianos podem chegar a Vênus, não há razão para supor que a humanidade não consiga o mesmo feito (...) Por outro lado, pode ser que a destruição dos marcianos tenha sido apenas um adiantamento da sentença. Talvez a eles, e não a nós, o futuro esteja reservado (grifos nossos). (Wells, 2007:235)
\end{abstract}

A utilização de múltiplos tempos verbais (passado, presente e futuro), efetivada na citação acima, torna o texto uma ação de esquematização temporal que transforma categorias abstratas em objetos de uma compreensão prática. O passado caracterizado como o tempo das certezas, o presente o momento da destruição das conviç̧ões e o futuro o tempo da desconfiança, da insegurança e da dúvida. A obra torna possível uma percepção temporal inteligível porque faz uma articulação entre o mundo do texto e o mundo fora dele.

Nas reflexões que fizemos até aqui, pudemos demonstrar o caráter de mediação que a obra exerce, por outro lado, demonstrou-se também que, ambos os estágios (mimese I e II) podem ser percebidos através dela. Aqui é necessário destacarmos que o mundo não está reduzido ao texto, contudo, está presente nele e pode assim ser lido a partir de sua mediação. 
Ao nos reportamos novamente a Wells, podemos perceber que há um desejo implícito de compreender as ações de seu tempo. Nesse movimento de ação e compreensão, organiza-se a composição de uma teatralidade de eventos que articula um movimento concordante/discordante.

Por fim, estabelece-se na obra um terceiro elemento de mediação quando ela efetiva uma outra temporalidade, como demonstramos anteriormente. Mas há também um diálogo entre dois outros tempos: o episódico e cronológico, que acaba por articular acontecimentos de rompimento e continuidade em uma ordem dialética, porém coerente. Não somente a efetivação de uma ação, mas a estruturação de um discurso que permite ao leitor compreendê-la como tendo um tema.

$\mathrm{Na}$ epopéia vivida pelos homens de Wells, uma questão permanece do começo ao fim do livro: o questionamento sobre as fragilidades da humanidade, assim como a incerteza de suas descobertas científicas como a garantia de um futuro previsível.

O livro é impregnado de citações científicas e de episódios surpreendentes que, a todo o momento, parecem prestes a fincar um problema incontornável para a história, entretanto, por sua dimensão configurante, "graças a qual a intriga transforma os acontecimentos em história" (Ricoeur, 1997:104), sua trama efetiva uma totalidade.

É dessa configuração que a trama extrai sua unicidade temporal na discordância concordante de suas partes, afinal, como bem nos lembrar Ricoeur (idem:105) "seguir uma história é avançar no meio de contingências e de peripécias sob a conduta de uma espera que encontre sua realização na conclusão".

A chegada dos marcianos é a primeira grande peripécia da história de Wells. É o episódio que representa, ao mesmo tempo, o início da sua intriga e também o marco temporal de uma sucessão de vários outros eventos extraordinários, que vão efetuando um movimento de distensão que estimula a expectativa pra o final.

Gostaríamos de destacar um último aspecto na obra de Wells que, a nosso ver, acaba por ligar mimese I a III e realizar o círculo hermenêutico de sua obra. Além de todos os componentes que discutimos até aqui, desde as estruturas mentais e culturais que informaram sua obra e que possibilitaram a composição de sua fantástica história, bem como os pressupostos reais extraídos de seu próprio contexto como guerras, invasões, há, em A Guerra dos Mundos, uma recorrência marcante; a invasão é narrada por um recurso midiático: a imprensa.

Wells constrói uma experiência bastante singular em sua obra: a composição de um acontecimento midiático ficcional. Progressivamente, vamos acompanhando como vários jornais e informativos, que circulam em seu mundo configurado, espalham a fantástica história dos invasores na Terra.
Há também um diálogo entre dois outros tempos: o episódico e cronológico, que acaba por articular acontecimentos de rompimento e continuidade em uma ordem dialética, porém coerente 
A cada episódio espetacular, o autor abre em seu texto pequenas notas jornalísticas que vão progressivamente auxiliando no seu trabalho de tessitura. A imprensa funciona então como um elo de verossimilhança entre o mundo do autor, o mundo de sua obra e o mundo do leitor. Wells joga, por conseguinte, com o lugar de legitimidade da imprensa de lidar com o real, para dar à sua obra ficcional o caráter de uma história crível, tanto interna como externamente.

Se em seu texto a chegada dos marcianos é divulgada nas páginas dos jornais, fora dele a imprensa representa o elo que o leitor de Wells irá utiliza para compreender, assimilar e agir sobre a obra. Por outro lado, aponta também para o papel desempenhado pela imprensa naquele contexto.

Ao se utilizar dos jornais em seu jogo narrativo, Wells lança mão de funções e artifícios legítimos atribuídos àquele veículo em seu cotidiano. Desta forma, temos uma idéia de como se dava o trabalho de mediação dos recursos midiáticos, demonstrandonos que uma obra ficcional pode ser lida como um instrumento revelador do contexto na qual foi elaborada.

Importante notar que o próprio romance saiu em capítulos em uma revista popular em 1897, para ser lançando na íntegra em 1898. Em sua obra há citações a jornais ou à imprensa, do primeiro ao último capítulo, narrando desde os primeiros contatos com marcianos até o melancólico fim em uma Londres desolada. Vejamos a seleção de alguns trechos abaixo:

Lembro da alegria de Markham ao conseguir uma nova fotografia do planeta para o jornal ilustrado que editava na época. As pessoas hoje mal imaginam a abundância e o espírito empreendedor dos jornais oitocentistas (p.37).

Por volta das onze, segundo relataram os jornais da manhã seguinte (...) cerca de 400 homens do regimento de Cardigam... partiram... (p.71).

Deixei-os ainda discutindo, e fui até a estação de trem para comprar todos os jornais matinais que eu pudesse encontrar (p.75).

Aqueles que ouviram demoraram para entender todo o significado dos telegramas escritos às pressas e publicados nos jornais de domingo. A maioria dos londrinos não lê as folhas dominicais (p.114).

Um grande temor tomou conta de West Surrey, e fortificações de terra estão sendo erguidas para deter o avanço em direção à Londres. Foi assim que o Sun de domingo deu a notícia (p.115).

Em todas as esquinas as pessoas liam jornais, discutiam apaixonadamente ou olhavam para os estranhos visitantes dominicais (p.120).

Não demorou para que homens com edições extraordinárias dos jornais chegassem à rua aos gritos: '- Londres pode ser esmagada! (...) (p.122).

Nesse jornal, meu irmão leu: (...) É impossível detê-los. A única proteção contra a Fumaça Negra é a fuga imediata (p.123). 
Podemos vislumbrar como as próprias notícias ficcionais constroem uma história que nos possibilita entender a trama em seus sobressaltos e peripécias, assim como, o caminho pra sua conclusão:

No canto da ponte vi também um dos contrastes (...) uma folha de jornal exposta (...) Era o cartaz do primeiro jornal que voltou a ser publicado, O Daily Mail (...) Estava quase todo em branco, mas o tipógrafo solitário que o diagrama divertia-se fazendo uma grotesca distribuição de clichês na última página. O material publicado era emocional, a organização das notícias ainda não voltou a ser o que era (229).

A atuação da imprensa, enquanto mecanismo de mediação, é, na verdade, um dos aspectos mais importantes na obra de Wells e, talvez, o menos percebido, porque há uma tendência à naturalização de seu papel. Contudo, é através dela que a invasão dos extraterrestres se torna conhecida no mundo do texto, por outro lado, representa as expectativas do autor e seus leitores sobre o papel que deveriam ter os jornais e informativos naquele contexto. Ao construir um acontecimento midiático ficcional, Wells nos chama atenção para o lugar que os meios de comunicação assumiriam naquela sociedade em transformação, assim como seu papel na mediação do real.

\section{A construção do acontecimento real na tessitura midiática}

In the thirty-ninth year of the twentieth century came the great disillusionment. It was near the end of October. Business was better. The war scare was over. More men were back at work. Sales were picking up. On this particular evening, October 30th, the Crosley service estimated that thirty-two million people were listening in on radios. (Welles: 1938.)

Passados 40 anos do lançamento do livro de H. G. Wells, outubro de 1938, em uma transmissão radiofônica, o apresentador Orson Welles dava notícia de uma invasão de extraterrestres sobre a terra. Welles caprichou nos efeitos sonoros, na gritaria das pessoas e colocou uma boa dose de nervosismo em sua dramatização. Evidentemente, a terra não estava sofrendo qualquer invasão o que, portanto, não era um acontecimento "verdadeiro". Entretanto, a adaptação ${ }^{2}$ do texto ficcional de H. G. Wells, passada para as pessoas que escutavam o programa naquele momento, produziu um acontecimento real, que foi o convencimento dos ouvintes sobre a veracidade da notícia.

Apesar de Welles ter avisado antecipadamente que se trataria de uma dramatização, muitos acreditaram na veracidade dos fatos narrados e seu programa se tornou um dos maiores
Wells nos chama atenção para o lugar que os meios de comunicação assumiriam naquela sociedade em transformação, assim como seu papel na mediação do real 
fenômenos da produção midiática do século XX. Inaugurou uma nova linguagem e efetivou de forma decisiva a transmissão do acontecimento em tempo real. O rádio quebrou a última fronteira de simultaneidade que separava pessoas em lugares distintos e distantes. Mais tarde tentaremos demonstrar como este fator servirá de maneira crucial na difusão de acontecimentos no mundo contemporâneo.

Ao nos determos ao feito de Orson Welles, inverteremos o círculo hermenêutico proposto por Ricoeur e consideraremos a transmissão radiofônica como o espaço de mimese III, mas que, ao mesmo tempo, representa a feitura de um novo círculo que enseja, necessariamente, uma nova tríplice mimese. Nesse caso, tentaremos demonstrar que, enquanto tal, esse círculo se apresenta sempre renovado, uma vez que "a narrativa tem seu sentido pleno quando é restituída ao tempo do agir e do padecer (...) mimese III marca a intersecção entre o mundo do texto e o mundo do ouvinte ou do leitor" (Ricoeur, 1997:110).

O tempo no qual a peça radiofônica de Orson Welles é encenada certamente estabelece referenciais dissonantes entre o tempo em que Wells lança sua obra, embora, cronologicamente, o espaço entre ambas seja relativamente curto. Com a primeira Grande Guerra, o que antes era apenas um receio no universo de Wells tornou-se realidade. As grandes nações européias tiveram seus territórios e suas economias praticamente devastadas com o conflito. Enquanto isso, do outro lado do mundo, os EUA se firmavam como nova potência, mesmo com a crise econômica.

As desilusões com o sistema capitalista com a queda da bolsa de Nova York trouxeram uma atmosfera bastante pessimista acentuando ainda mais as incerteza em relação ao futuro. Alguns arquétipos, no entanto, continuavam a fazer parte, vivamente, daquele universo mental e cultural. As expectativas sombrias de um novo conflito, assim como, o fascínio pelas descobertas científicas e as especulações sobre a possibilidade de vida em outros planetas permaneceram como campo fértil naquele contexto. No fim da década de 30 do século XX, efetivam-se os poderosos sistemas comunicacionais ampliados, sobremaneira, pelo clima belicoso que ansiava pela formação de opinião através da divulgação de informações.

Nesse mundo efervescente, a circulação de informações como mercadoria tornou-se uma prática. Sobre esse aspecto Thompson (2004) afirma que ao se constituir um público regular de consumidores desses produtos, foram também estabelecidos novos padrões de apropriação destes bens. No século XX, a ampliação do processo trouxe à tona a discussão acerca do desenvolvimento de uma comunicação de massa, como sendo um amplo processo de difusão e distribuição desses recursos tanto em termos de espaços como de receptores, o que a experiência no rádio, realizada por Orson Welles, colocará em cena.

2"A peça radiofônica é de autoria de Howard Koch com a colaboração de Paul Stewart, baseada na obra de H.G. Wells (1866-1946), e ficou conhecida como 'rádio do pânico'. O roteiro foi reescrito pelo próprio Orson Welles." In ORTRIWANO, Gisela Swetlana. A invasão dos marcianos: A Guerra dos Mundos que o rádio venceu. Boletim No. 24 Série eletrônica Janeiro-Fevereiro, 1999 Capturado no endereço do site http://www.igutenberg.org/ guerra124.html. 
A estruturação de uma indústria cultural, pensada de forma articulada entre as necessidades de mercados consumidores de bens simbólicos e materiais, ocorre entre os séculos XIX e XX. Thompson destaca três momentos nesse processo: o primeiro deles, ainda no início do século XIX. Com a redução de impostos e o barateamento na produção jornalística houve um grande impulso da imprensa nesse século, fazendo com que os jornais se tornassem enormes empreendimentos comerciais que movimentavam grandes quantidades de capitais.

O segundo momento ocorre com a globalização da comunicação, que remonta a meados do XIX, quando "o fluxo internacional de informação e de comunicação assumia uma forma muito mais extensiva e organizada" (Thompson, 2004:75). Estes dois momentos estão vivamente presentes na tessitura de H. G. Wells lembremos como, rapidamente, a história da invasão se espalha entre cidades e países nas notícias vinculadas nos jornais.

Por último, o terceiro momento com o surgimento da energia elétrica, que proporcionou as transmissões de rádio (1920) e televisão (anos 40). Isso sem levarmos em conta o surpreendente fluxo de informação operado através dos modernos sistemas postais, telégrafos, ferrovias, rodovias e o telefone, este último um parceiro capital na difusão de notícias.

Este complexo amálgama de referenciais simbólicos e culturais torna possível a apropriação de uma obra em diversos momentos, com sobreposições de sentidos que oscilam entre a tradição, inovação e a sedimentação de antigos e novos paradigmas. Por conseguinte, sua configuração temporal engendra um complexo movimento dialético que nunca se esgota em si.

Mas, se a narrativa livra-se da acusação de realizar uma violência interpretativa, na qual imporia uma temporalidade estática ao mundo fora do texto, realizar-se-ia em Mimese III o mesmo efeito de sentido produzido em Mimese I, haveria, por conseguinte, uma redundância interpretativa presente na obra? Pensando nos dois momentos narrativos com os quais trabalhamos aqui, $A$ Guerra dos Mundos de H. G. Wells e a peça radiofônica de Orson Welles efetivariam uma mesma semântica da ação?

Neste ponto Ricoeur é categórico ao afirmar que não é a obra que impõe uma dada narração sobre a vida, mas é a necessidade humana de narrar e contar histórias que constrói enquanto tal, sendo a obra seu produto. Cada sociedade, grupo humano ou indivíduo está imerso em um emaranhado de histórias não contadas, não sistematizadas, "a conseqüência principal dessa análise existencial do homem como ser emaranhado em histórias é que narrar é um processo secundário, o do tornar-se conhecido da história (...). Narrar, seguir a compreender histórias é só a continuação dessas histórias não ditas" (Ricoeur, 1997:116).
A estruturação de uma indústria cultural, pensada de forma articulada entre as necessidades de mercados consumidores de bens simbólicos e materiais, ocorre entre os séculos XIX e XX 
O programa do jovem apresentador Orson Welles trouxe à tona um emaranhado de várias histórias presentes naquele contexto, além de uma compreensão sobre a estrutura de ação de um recurso midiático como o rádio. Welles joga com um conjunto de informações que sobejavam em seu universo. Não somente em termos de imaginários sobre especulações científicas, mas, principalmente, com a expectativa que as pessoas tinham sobre o papel do rádio, na verdade ele negocia com o lugar de legitimação de produtor de notícias e faz com que seu texto ficcional torne-se um evento crível e verossímil para seus espectadores.
Cada sociedade, grupo humano ou indivíduo está imerso em um emaranhado de histórias não contadas, não sistematizadas

\begin{abstract}
Aproveitando a credibilidade que o jornalismo havia conquistado, e apoiado nos recursos reais disponíveis em 1938 e aos quais os ouvintes estavam acostumados, o padrão dramático foi utilizado para o desencadeamento da obra radiofônica. [...] A introdução de reportagens externas merece destaque, uma vez que possibilitava as transmissões dos acontecimentos jornalísticos ao vivo, diretamente do palco da ação, do local em que ocorriam. [...] (Ortriwano, 1999).
\end{abstract}

No retorno da obra H. G. Wells ao mundo, ou seja, o espaço de Mimese III, vemos um novo arranjo de sentido, mas que ao mesmo tempo consegue dialogar com elementos presentes desde Mimese I, o lugar de onde a obra parte. O texto adaptado por Orson Welles para o rádio consegue ser compreendido não porque o abra literária de H. G. Wells traz valores intrínsecos imutáveis entendidos em todos os contextos humanos; ao contrário, ela efetiva um novo contrato de verossimilhança no contexto ao qual se apresenta.

$\mathrm{Na}$ medida em que a obra desencadeia componentes concordantes/discordantes, a cada novo círculo articula-se uma possibilidade de constante leitura, todavia, nunca da mesma maneira, muito menos, há uma quebra total de seus fundadores de sentido iniciais, dessa forma "o círculo hermenêutico entre narrativa e tempo não cessa assim de renascer do círculo que os estágios de mimese formam" (Ricoeur, 1997:117).

Há, conseqüentemente, sempre uma configuração e uma reconfiguração que se dá em um processo de leitura da obra. O roteiro de Orson Welles representa uma leitura da obra de H. G. Wells, mas que nos serve como rastro deixado por dois mundos. Por sua vez sua própria adaptação se constitui o início de um novo círculo mimético da obra. Entre a dialética da esquematização e do tradicionalismo a obra trabalha com paradigmas que estruturam as expectativas do leitor/ouvinte.

No script produzido para ir ao ar em 1938, A Guerra dos Mundos ganha uma nova configuração adequada tanto ao novo recurso de mediação, não mais um livro, mas um programa de rádio, como também evidencia um novo mundo para o qual a obra retorna, dessa maneira, o conteúdo comunicado, para além do sentido 
da obra, coloca em relevo um mundo que é projetado como horizonte. "Nesse sentido, o ouvinte ou o leitor recebem segundo sua própria capacidade de acolhimento que, também ela, define-se por uma situação ao mesmo tempo limitada e aberta a um horizonte de mundo" (Ricoeur, 1997:117).

O que torna, portanto, um acontecimento tão extraordinário e inverossímil, ser aceito como fato verdadeiro, transpõe o próprio universo da obra e situa-se novamente no mundo fora dela. Assim como em Mimese I é o mundo que empresta todos os fundadores de sentido presente para o texto, o mesmo ocorre em Mimese III, quando a obra se dá ao mundo.

No momento de sua recepção são colocados em movimento novamente referenciais os mais diversos, que acolhem ou rejeitam a trama em um movimento de intentio e distentio que somente pode ser compreendido através da ação e da própria experiência humana.

Todas as características com as quais os ouvintes estavam acostumados em programas radiofônicos foram utilizadas por Orson Welles. Entrevistas, depoimentos. Um aspecto importante sustenta o potencial de verossimilhança do evento, a constante presença de "especialistas" que são, a todo o momento, chamados para explicar o que ocorria.

We are ready now to take you to the Princeton Observatory at Princeton where Carl Phillips, our commentator, will interview Professor Richard Pierson, famous astronomer. (...)Professor, would you please tell our radio audience exactly what you see as you observe the planet Mars through your telescope? (Welles, 1938).

O processo de tessitura do programa radiofônico efetiva-se sobre um horizonte de possibilidades tanto internas, quanto externas. Interna porque se constrói com referências de significações que o estruturam em um todo que embora seja marcado por um movimento dialético, enseja uma coerência organizativa. Externa porque estabelece uma ligação com o mundo que jamais pode ser tomado como mero objeto de discurso, uma vez que, "as obras de ficção só pintam a realidade aumentando-a com todos os significados que elas próprias devem às suas virtudes" (Ricoeur, 1997:123).

\section{A construção do acontecimento histórico entre dois mundos - a literatura e a mídia.}

Ouvintes de rádio em pânico tomam drama de guerra como verdade. Manchete do jornal New York Times de 01.11.38 (Ortriwano, 1999).

O programa de rádio, narrando a invasão dos extraterrestres, durou apenas uma hora na noite do dia 30 de outubro de 1938, mas foi escutado por cerca de seis milhões depessoas, das quais 
1.2 milhão acreditaram ser a "notícia" um fato real. Tal como no texto literário de H. G. Wells, quando os habitantes das pequenas cidades da Inglaterra fugiam de suas casas ao serem informados pelos jornais matutinos sobre os invasores, os moradores de Newark, Nova Jersey e Nova York, nos Estados Unidos, fugiram, tumultuosamente, de suas casa para não serem exterminados.

Nesse episódio há dois aspectos fundamentais a serem considerados: o primeiro deles nos demonstra que o poder de mediação de uma narrativa transpõe a mera textualidade e atua como objeto de ação no mundo, por outro lado, nos faz perceber que, partido dele, ela realiza um movimento dialético de adaptações. Em segundo lugar, destacamos o papel de um recurso midiático como veículo nessa mediação e na estruturação de um acontecimento. Guerra dos Mundos se tornou um acontecimento emblemático para a história dos meios de comunicação no século XX, que colocou em xeque as fronteiras entre realidade e ficção na divulgação de notícias e chamou atenção para o papel que estes meios podem exercer.

Entre a obra literária de H. G. Wells e o texto midiático de Orson Welles uma grande e complexa rede de significações sociais e culturais foi colocada em movimento, para que as duas se tornassem histórias aceitas e inteligíveis entre grupos e sociedades que comungavam de recursos semânticos e temporais com os quais puderam operar com cada um dos textos.

Pudemos perceber a profunda aproximação entre realidade e ficção, fazendo dos textos um emaranhado de estruturas simbólicas que ajudaram a compor estatutos de verossimilhança, coerência, imaginação e ação. Por outro lado, ambas colocaram em cena também um tumultuoso movimento de concordância/discordância sem o qual a narrativa jamais poderia efetivar seu círculo hermenêutico.

A obra do jovem apresentador Orson Welles, apesar de ter uma base ficcional, o romance de George Wells, trouxe à tona uma série de características sociais presentes naquele contexto histórico, mais do que isso, desencadeou um conjunto de eventos e produziu aquilo que conhecemos por acontecimento histórico, uma vez que tal evento transpôs a mera temporalidade de seu contexto e passou a ser conhecido, refletido e interpretado por outras gerações. Orson Welles conseguiu fazer da sua narrativa, ao mesmo tempo, objeto de memória e de história.

Partimos deste ponto para discutir de que maneira se relacionam realidade e ficção na produção de informações e formas de conhecimento na atualidade. Antes, uma questão é necessária: o que concede o caráter de histórico a dado acontecimento?

Em nossos dias, responder a esta pergunta é ainda mais difícil quando nos deparamos com uma desmesurada produção de informações que interfere na compreensão e na formulação dos
Pudemos perceber

a profunda

aproximação entre realidade e ficção,

fazendo dos textos

um emaranhado de estruturas simbólicas que ajudaram a compor estatutos de verossimilhança, coerência, imaginação e ação 
acontecimentos contemporâneos. A noção de simultaneidade, antes só possível em espaços extremamente restritos, tomou proporções gigantescas. Um exemplo claro disso pode ser observado no programa radiofônico de Orson Welles.

Por outro lado, hoje, os meios de comunicação ajudam a elaborar uma idéia de acontecimento que é pensado no momento de sua efetivação como histórico. Imprensa, rádio, televisão e internet são suas próprias condições de existência, mas o fato de terem acontecido não os torna histórico, para tanto, é necessário que eles sejam reconhecidos enquanto tal e isso implica a informação que se elabora sobre eles.

Hoje, nos acostumamos a assistir ao acontecimento espetáculo elaborado pela palavra, o som e a imagem, o que estimulou em nossa sociedade uma verdadeira fome por novidades, fazendo com que alguns meios de comunicação se tornassem verdadeiras fábricas de produção de acontecimentos. Verdade e ficção misturam-se em um mundo de ansiedades nunca saciadas.

Os acontecimentos veiculados pelos meios de comunicação são também práticas discursivas que modelam e representam a realidade sob um dado olhar. Realidade em si, impossível de ser vislumbrada em sua totalidade. Nenhuma pessoa ou grupo é capaz de apreendê-la em suas infinitas nuances e, mesmo o que é possível de ser trabalhada, precisa ser apropriada em categorias cognitivas e teóricas.

Dessa maneira, o acontecimento moderno emerge amparado por uma grande rede de comunicação, que coloca em evidência algo muito parecido com o ideário do fato positivista. Este acontecimento midiático apresenta-se como o evento indomável "porque a redundância intrínseca ao sistema tende a produzir o sensacional, fabrica permanentemente o novo, alimenta uma fome de acontecimento" (Nora, 1995:183).

Um componente, entretanto, parece querer resistir no coração do monstro acontecimental contemporâneo: a imagem de uma verdade objetiva quase absoluta que ainda tenta efetivar a radical separação entre realidade e imaginação. A despeito disso, a elaboração da informação e do conhecimento histórico só é possível com a intermediação de diversas visões de mundo, estruturas culturais e mentais.

Percepções que modificam significados ao mesmo tempo em que estabelecem outros e que são suficientemente fortes para transformar eventos em acontecimentos históricos, sociais, políticos etc. Assim como os eventos passados podem ser representados de várias maneiras pelos historiadores, os acontecimentos apresentados pela mídia são fruto de uma série de conformações políticas, sociais, econômicas que os fazem ser o que são.

Ao vislumbrarmos estas formas narrativas (literatura, mídia e história) pudemos compreender como, em suas feituras, dialogam várias categorias de percepção do real num jogo dinâmico e tumul-
Nos acostumamos

a assistir ao acontecimento espetáculo elaborado pela palavra, o som e a imagem, o que estimulou em nossa sociedade uma verdadeira fome por novidades 
tuoso de signos e referenciais. Nas três um agente é essencial: a ação narrativa. Para além das formas sob as quais um conhecimento ou uma informação se organizam: um romance, uma notícia ou um texto histórico, é somente no ato de narrar que seus conteúdos adquirem sentido e explicação. Isso não significa dizer que a textualidade se sobrepõe à vivência ou às práticas humanas, mas sim, que o próprio ato de narrar é uma ação puramente humana. É pela necessidade de tecer narrativas, numa busca compreensão sobre suas próprias ações no tempo, que os vários grupos contam histórias.

Ao nos debruçarmos sobre os acontecimentos contemporâneos devemos levar em consideração que estes são escolhas, elaborações sociais carregadas de interesses e visões de mundo. Diferentemente de seccioná-los em categorias conceituais fechadas, vê-los somente em termos da separação radical entre realidade e ficção, devemos levar em consideração que todo e qualquer acontecimento é elaborado em uma rede na qual há um cruzamento desses vários fatores. São eles que corroboram para sua efetivação e, para compreendêlos, devemos partir não de dimensões dicotômicas, ou mundos em guerra, mas sim considerar que todos esses elementos servem na construção dos seus significados. Tecer uma narrativa é por fim, uma busca de compreensão sobre a própria vida.

\section{Referências}

ELIAS, Norbert. O Processo Civilizador - Uma História dos Costumes Trad. Rui Jungmann. VOL.I. Rio de Janeiro: Zahar, 1997.

GEERTZ, Clifford, A Interpretação das culturas. Rio de Janeiro: Editora Guanabara, 1978.

HARTOG, François. Regime de Historicidade. Capturado da Internet em 8/05/2006 no endereço: http://www.fflch.usp.br/dl/heros/excerpta/hartog.html.

NORA, Pierre \& LE GOFF, Jacques. Novas Abordagens. Rio de Janeiro: Francisco Alves, 1995.

NORA, Pierre. O Retorno do Fato in NORA \& LÊ GOFF. Novos Problemas. Rio de Janeiro: Francisco Alves, 1995.

ORTRIWANO, Gisela Swetlana. A invasão dos marcianos: A Guerra dos Mundos que o rádio venceu in Instituto Gutenberg Boletim No 24 Série eletrônica Janeiro-Fevereiro, 1999. Capturado de endereço na Internet: http://www.igutenberg.org/guerra124.html em 25 de maio de 2007.

RICOEUR, Paul. Tempo e Narrativa. Tomos I, II, III, São Paulo: Papirus Editora, 1997.

RÜSEN, Jörn. Razão Histórica - Teoria da história: os fundamentos da ciência histórica. Brasília: Editora UNB, 2001.

THOMPSON, John B. Mídia e Modernidade: uma teoria social da mídia. São Paulo: Vozes, 2004.

WELLS, H. Georg. A Guerra dos Mundos. Alfaguara/Objetiva. 2007.

WELLES, Orson. Scrip - "The War of the Worlds" by H. G. Wells as perfor-

Estudos em Jornalismo e Mídia - Ano VI - n. 1 pp. 53 - 69 jan./jun. 2009 
med by Orson Welles \& the Mercury Theatre on the Air and broadcast on the Columbia Broadcasting System on Sunday, October 30, 1938. Capturado da Internet no endereço http://members.aol.com/jeff1070/script.html em 31/ de março de 2007.

Recebido em 11 de fevereiro de 2009 Aprovado em 4 de maio de 2009 